Preprints of the

Max Planck Institute for

Research on Collective Goods

Bonn 2006/23

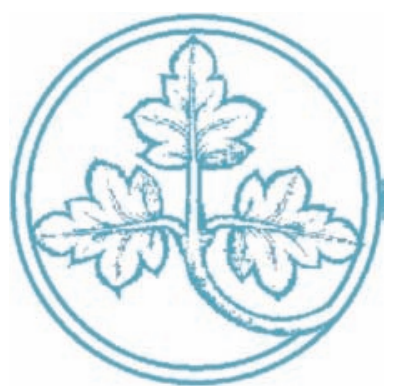

Ex Interim Voting in

Public Good Provision

Sven Fischer /

Andreas Nicklisch

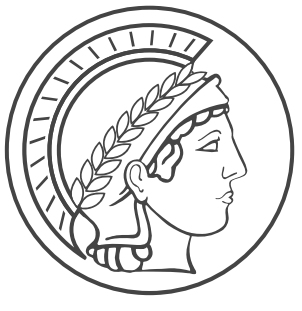




\title{
Ex Interim Voting in Public Good Provision
}

\author{
Sven Fischer / Andreas Nicklisch
}

September 2006 


\title{
Ex Interim Voting in Public Good Provision
}

\author{
by \\ Sven Fischer AND ANDREAS NiCKLISCH*
}

\begin{abstract}
We report the results of an experimental study that compares voting mechanisms in the provision of public goods. Subjects can freely decide how much they want to contribute. Whether the public good is finally provided is decided by a referendum under full information about all contributions. If provision is rejected, contributions are reduced by a fee and reimbursed. We compare unanimity with majority voting and both to the baseline of cheap talk. Contributions are highest under unanimity. Yet, results concerning overall efficiency are mixed. When provision occurs, only unanimity enhances efficiency. Overall, however, unanimity leads to too many rejections. (JEL: C 72, C 91, H 41)
\end{abstract}

\section{Introduction}

Public goods are a central and extensively researched problem in economics. There is an enormous amount of theoretical and experimental literature. Much of the theoretical literature tries to find a mechanism in order to solve the free-rider problem (e.g., via an optimal tax mechanism as in GROves AND LEDYARD [1977]). Experimental research on public goods centers around the voluntary contribution mechanism (VCM). Experimental behavior of the majority of players differs substantially from the individually rational solution. Several studies on simple linear public good games demonstrate that only a minority of subjects free-ride, while the overwhelming majority behave as conditional cooperators (e.g., FischBACHER, GÄCHTER, AND FEHR [2001]). Conditional cooperators increase their own contribution as the contributions of others increase.

By cooperating in providing a public good, agents can jointly increase their individual payoffs. However, cooperation always entails a risk of exploitation. If one could condition one's own contribution on that of others, this, of course, could be avoided. Yet, how do we deal with the risk that cooperation will be exploited? Are there mechanisms which diminish this risk? The economic literature offers several approaches: sequential contribution announcements (e.g., MoXnES AND

*The authors would like to thank the participants and the discussants at the Bad Meinberg conference, and René Levinsky for valuable comments and suggestions. 
Van der Heijden [2003], Potters, Sefton, And Vesterlund [2005]), regrouping of players according to their previous contributions (e.g., EHRHART AND Keser [1999], Page, Putterman, and Unel [2005]), intergenerational advising among players (e.g., Chaudhuri, Graziano, And Maitra [2006]) or ex post punishment/reward mechanisms, which allow participants to de-/increase others' payoffs at their own cost (e.g., Ostrom, Walker, And Gardner [1992], Fehr AND GÄCHTER [2000]). The results of the sequential contribution announcements indicate a high correlation between contributions of leaders (players who announce their contributions first) and followers ${ }^{1}$ while advising, regrouping and punishment mechanisms increase contributions quite substantially.

Our study follows a different approach. We combine a linear public good game with a subsequent voting stage. After all, in every democracy most public goods are decided upon via referendums. LEDYARD AND PALFREY [2002] give a theoretical justification for the ubiquitous use of referendums. They prove that under certain conditions the performance of an interim efficient ${ }^{2}$ public good mechanism can be approximated by referendums. A broad empirical literature has examined the various aspects of referendums for the allocation of public resources (e.g., Romer, Rosenthal, And Munley [1992]). While in most cases referendums are held with a limited number of elected representatives, special interest has been directed towards the cases in which referendums are held with the entire electorate (on the level of municipalities as the most prominent example in Switzerland, see FREY [1994]). Indeed, empirical studies provide evidence that public good provision is more efficient in direct democracies (e.g., Pommerehne [1978], Feld and Matsusaka [2003]).

There are several ways referendums can be implemented in public good game experiments. Generally, one can distinguish between ex ante, ex interim, and ex post voting mechanisms. Ex post voting mechanisms allow participants to decide upon the structure of the public good game in the consecutive period, for example, by voting to ostracize a particular player (e.g., MAsclet et al. [2003], Cinyabuguma, Page, AND Putterman [2005]). ${ }^{3}$ Ex ante voting refers to mechanisms which, e.g. allow group members to decide about the introduction of a fee mechanism before they determine their contributions (e.g., FELD AND TyRAN [2002]). This article, however, concentrates on ex interim voting. Here, players decide on the provision of a public good after they have contributed. If the voting mechanism rejects provision, contributions are reimbursed. Based on the particular decision rule, the ex interim mechanism allows us to manipulate the risk of exploitation.

So far there has been little research on ex interim voting in public good provision. The authors of this study are only aware of the paper by BANKS, PLOTT, AND PORTER [1988]. They (among others) compare the performance of a VCM with a

\footnotetext{
${ }^{1}$ Of course, here the exploitation problem for leaders remains unsolved.

${ }^{2}$ For a definition of interim efficiency in public goods, see LEDYARD AND PALFREY [1999].

${ }^{3}$ For a theoretical model applying ostracism, see HirshleIfER AND RASMUSEN [1989].
} 
VCM with posterior unanimity voting. Subjects either play a public good game by only deciding how much to contribute, or by first deciding upon their contribution before voting on whether, with the given and known contributions, the public good should actually be provided. Only if all vote for the installation is the public good finally paid to the players. The experiments find that, while contributions in the referendum treatment are higher, over all efficiency decreases as the unanimity mechanism leads to many rejections. Although there are cases in the real world with an unanimity voting rule, the most prominent case is that of majority voting. This is why, in this paper we compare the efficiency of a majority to that of a unanimity referendum.

In a very stylized form this is related to a recent discussion concerning the modus operandi of the European Union. Since it's enlargement to 25 member states, there is an intensive discussion as how to change the rules for decision finding in order to cope with the increased number of members (see, e.g., Schimmelfennig And SEDELMEIER [2002]). In the past many decisions could only be made unanimously. Since it's enlargement from 16 to 25 members, it is now argued that the EU will be unable to make decisions on important issues. It is thus argued that the majority rule should be applied to several topics and problems. An important question albeit one that is often ignored in this context is which method leads to better decisions.

Obviously, a union of nations is a much more complicated thing than a simple public good game. However, in a very stylized way, the purpose of a union is to jointly create a public good. States coordinate in order to create a common market, a monetary union or else because they at least think that this benefits all of them. But how do they contribute to this common good? Besides monetary payments, member states pay by political effort, by giving up sovereignty and by allowing economic powers to be shifted.

Another very recent example is the effort by members of the United Nations to create a military force in order to supervise the truce in the Democratic Republic of the Kongo during the coming elections. In this case, member states first name the size of their contingent before voting unanimously on whether this is sufficient to actually justify engaging in that war torn region.

In this study we introduce a standard model for a public good game with voluntary contribution levels but ex interim voting in which these is complete information on whether the public good is actually being provided. We compare unanimity and majority voting to a baseline treatment with automatic provision. If the provision of the good is rejected, contributions are reimbursed, yet a small fee is extracted as a transaction fee. We test our model of public good provision in a series of laboratory experiments where subjects repeatedly play our game for a finite number of periods. Although there are many aspects which may affect the efficiency of the two voting mechanisms in this context, we, for now, abstain from introducing more than our single treatment, the voting mechanism.

This paper is organized as follows: In section 2 we introduce the model. Furthermore, we elaborate hypotheses for players' behavior and discuss counter-arguments. 
Section 3 reports the experimental design, section 4 the results of the laboratory experiments, and section 5 concludes the paper with a discussion of the findings.

\section{Public Good Game with Ex Interim Voting}

In the following we introduce our public goods model. By and large we reduce the public goods problem to what we view as its most important aspects. More specifically, for example, we neither introduce different contribution costs nor non constant (decreasing) marginal productivity of the public good (e.g., as in SMITH [1980]). We rather rely on the most simple model as, for example, analyzed by IsaAC, McCue, And Plott [1985]. We also keep the voting stage as simple as possible by using equal voting weights.

\subsection{The Game}

We define a simple $n$-person linear public good game. More specifically, there are $n \geq 2$ players, each of whom can contribute to a linear public good. Each player $i$ receives an initial endowment of $e_{i}>0$. We denote player $i$ 's contribution to the public good by $g_{i}\left(0 \leq g_{i} \leq e_{i}\right)$ and the sum of contributions of all players by $G$. Further, the marginal rate of per capita return of the public good, denoted as $\alpha(1 / n<\alpha<1)$, is identical for all players. After each player determines his contribution, she is informed about the contributions by others and decides on her vote $^{4} \varphi_{i}$ such that

$$
\varphi_{i}= \begin{cases}1 & \text { if player } i \text { votes for the public good } \\ 0 & \text { otherwise }\end{cases}
$$

Whether the public good is provided after the vote depends on the voting mechanism. The voting operator $\Phi$ is defined as a function of the set of all votes $\varphi=\left\{\varphi_{1}, \varphi_{2}, \ldots, \varphi_{n}\right\}$ as

$$
\Phi(\varphi)= \begin{cases}1 & \text { if the public good is provided } \\ 0 & \text { otherwise }\end{cases}
$$

We introduce a fee $f$, which has to be paid by those who promised a positive contribution if the public good is not provided. Thus, in conflict only those who wished to contribute have to pay it. One could think of this fee as transaction or opportunity costs, for example, in the sense of lost interest. Alternatively, fee $f$ represents the costs of conflict that only concern those who intended to create a public good $\left(g_{i}>0\right)$ in the first place. More specifically, if the public good is

\footnotetext{
${ }^{4}$ Of course, one may argue that only those players should be allowed to vote who contributed. However, players perhaps do not want the good to be provided, so they do not contribute and, furthermore, veto the provision.
} 
rejected, all players who contributed have to pay the same fee, which, however, never exceeds their contribution $\left(f \leq g_{i} \forall i\right)$; that is, $f$ equals the smallest possible positive contribution, $f=\min _{k}\left\{g_{k} \mid 0<g_{k} \leq e_{k}\right\}$. Of course, the fee is common knowledge at the beginning of the game.

Therefore, defining $\delta_{i}=\operatorname{sign}\left(g_{i}\right)$, player $i$ 's payoff equals

$$
\pi_{i}=e_{i}+\Phi\left(\alpha G-g_{i}\right)-(1-\Phi) \delta_{i} f
$$

We compare two voting mechanisms: unanimity voting versus majority voting. The unanimity voting mechanism is defined as follows

$$
\Phi(\varphi)= \begin{cases}1 & \text { if } \sum_{i=0}^{n} \varphi_{i}=n \\ 0 & \text { otherwise }\end{cases}
$$

whereas for the second mechanism we use the simple majority rule, i.e.

$$
\Phi(\varphi)= \begin{cases}1 & \text { if } \sum_{i=1}^{n} \varphi_{i}>\frac{n}{2} \\ 0 & \text { otherwise }\end{cases}
$$

Our equilibrium analysis concentrates on subgame perfectness. Clearly the voting stage has multiple equilibria. For example, assume that endowments are symmetric and everybody fully contributes. Under unanimity, as everybody profits from provision, acceptance by all then constitutes a strict equilibrium. However, also rejection by two or more constitutes a voting equilibrium, this time, however, only in weakly dominated strategies. There are, however, good reasons to exclude these equilibria in weakly dominated strategies. As long as the game, as in our experiment, is not played in an environment with an infinite horizon the most obvious ones are the weak incentives and the inherent coordination problems.

We implicitly exclude these equilibria in weakly dominated strategies by assuming that subjects vote "sincerely". That is, we assume that subjects always vote for (against) provision if they earn more (or less) if the public good is provided than if it is not. We, furthermore, assume that subjects vote for provision if indifferent. Subsequently and due to fee $f$, provision in the remaining subgame perfect equilibrium of the game is not different from that of the standard game (for a proof, see Appendix).

Proposition 1 Assuming "sincere" voting behavior, equilibrium provision of all agents equals zero, independent of the voting mechanism.

Note that, (independently of our "sincere" voting assumption) without fee $f$, our game would allow for equilibria with different contribution profiles. Here, two or more maximum contributers with equal contributions were indifferent between provision and reimbursement. 


\subsection{Hypotheses}

There exists overwhelming evidence from both one-shot and repeated experiments of the public goods games that the subgame perfect equilibrium rather poorly describes the behavior. Therefore, it seems plausible that we cannot verify Proposition 1 by experimental data. Rather, we have to consider positive contributions even in the finitely repeated game. The voting mechanism subsequent to the contribution decision can be see as a safeguard against others' free-riding. Apparently, under unanimity there is no risk of exploitation by (partial) free riders since a single veto suffices to avoid provision.

Under majority voting, the safeguard effect is lower than under unanimity. There is a potential exploitation of a minority. Consequently, one might expect that contributions would tend to be lower under majority voting than under unanimity. Nonetheless, contributions under majority voting are higher than in a public good game without any voting mechanism.

This conclusion can also be drawn by allowing for imperfect expectations in combination with reasoning of a limited depth. In saying that reasoning is of a limited depth we mean that subjects only adjust their own contribution by playing best reply with respect to their imperfect expectations. Given the same initial expectations ${ }^{5}$ concerning the set of contributions by all the participants expect for oneself, the contribution of the highest contributer - who must be held indifferent according to one's own best reply function - is under the majority mechanism, at most as high as under unanimity. Consequently, one's own best reply under unanimity must be at least as high as under majority voting. ${ }^{6}$ If there is no voting mechanism at all, the free riding incentive is much higher, as it is dominant to always contribute nothing. We summarize these regularities in the following behavioral hypothesis:

HYPOTHESIS 1 Under the unanimity voting mechanism, contributions are not smaller than under the majority rule, where, in turn contributions are not smaller than in the same public good game in which there is automatic provision but no voting mechanism.

Considering the observations already made by BAnks, Plott, And PorTer [1988], we expect that for the same contribution behavior, unanimity voting is more likely than majority voting to end in rejection of provision. Consequently, an increased risk of exploitation is accompanied by an increase in the acceptance of exploitation as well.

Hypothesis 2 For the same contribution behavior, provision occurs more often under majority voting than under unanimity.

\footnotetext{
${ }^{5}$ Behaviorally one can think of the initial expectations as a subjective idea about what each subject would see as an 'ideal' contribution.

${ }^{6}$ See equations (A4) and (A7) in the appendix.
} 
Of course, the question now arises as to which mechanism is more efficient in the sense of the final overall size of the public good. Given the two previous hypotheses, it is hardly possible to make a statement concerning the overall effect. However, given the instability of minimum agreeing coalitions, coordination under majority voting is much more difficult, suggesting:

Hypothesis 3 Overall efficiency is higher under unanimity than under majority voting.

\section{Experimental Design}

As already mentioned, there are several aspects in a public good game with ex interim voting which may affect behavior and thus the efficiency of the voluntary public good provision. Besides the voting mechanism itself, the number of subjects, the possibility of communication (or the number of possible coordination stages), as well as asymmetries in endowments, the costs of provision, the marginal productivity of the good or voting weights, may influence the overall outcome. For now, we ignore such aspects and compare behavior with the following very simple design.

Our only treatment variable is the voting rule whose three conditions - unanimity $(\mathrm{UN})$, majority (MA) and no referendum, that is, automatic provision (NO) - are compared between subjects. Thus, each subject only plays one of the three treatment conditions. The reason for this choice is straight forward. Public good games are known for their restart effects. Thus, comparing three treatment conditions within subjects would require that all six possible sequences be tested.

As in many other public good experiments, subjects repeat the game they play ten times with the same group members before being matched to new groups using a perfect-stranger design and playing again 10 rounds.

Subjects were first handed general instructions describing in detail a public good game without any referendum. Then they had to answer a control questionnaire, which was designed to make subjects more acquainted with the game. Subjects who could not answer the questionnaire correctly were excluded from the remaining experiment. Only then were subjects given instructions describing the entire game, including the voting stages. Except for one small paragraph, these instructions were identical for all three treatment conditions. All instructions were read aloud. ${ }^{7}$

In the computerized experiment itself, in each period players first chose their intended contribution to the public good. Thereafter they were informed about the contributions of each other group member and about each subject's payoff, once in case of the provision of the public good and once in case the contributions are reimbursed. ${ }^{8}$ Then they were asked to vote for or against the provision of the

\footnotetext{
${ }^{7}$ For a translation of the instructions, see Appendix B. Questionnaires, and experimental data are provided by the authors on request.

${ }^{8}$ Also in the NO treatment condition, subjects were informed about these two possible outcomes with a note stressing that reimbursement is only a hypothetical option.
} 
public good. Finally players were informed about the results of the voting stage and their resulting earnings in that period. Hereby subjects were able to identify both, (intended) contributions and voting behavior of each group member.

In detail, our groups consisted of $n=5$ subjects, who each could at most invest their entire endowment of $e=20$. Only integer contributions were allowed. The marginal per capita return of the public good was $\alpha=0.4$ since this value is often found in the experimental literature about public goods and offers us the opportunity to compare our results with previous studies. Finally, the fee equalled the smallest possible positive contribution, that is $f=1$. Total experimental payoffs were accumulated over periods. The only difference between the three treatment conditions was the rule applied to the manifested votes. Note that in the NO condition subjects also submitted a vote which was communicated to all group members, but had no effect on the final outcome. It is, however, of utmost importance also to let subjects vote and to make these votes public, as otherwise it would be impossible to compare $\mathrm{NO}$ with UN and MA.

\section{Experimental Results}

In total, 4 sessions for each of the three treatment conditions with 25 subjects each were conducted in the experimental laboratory of the Max Planck Institute of Economics in Jena. Subjects were students of various fields recruited from Friedrich Schiller University Jena, of which about $38 \%$ had never participated in an experiment at the experimental laboratory in Jena before. Experiments were computerized using z-Tree software (FISCHBACHER [1999]), and recruitment was organized by the software package ORSEE (GREINER [2004]). No subject participated in more than one session; average earnings were 9.11 Euro (with a standard deviation of 1.36); and sessions lasted approximately 75 minutes (including admission and payment).

For the first ten periods ("subsession 1") we have 20 independent group observations for each treatment condition. After the restart (period 11 to 20, "subsession 2 ") strict statistical analysis would require taking an entire session as one independent matching group observation. That would leave us with four observations per treatment condition. However, in the following analysis, we will neglect the possibility that dependence resulting from interaction in subsession 1 carries over to a dependency of not interacting subjects in subsession 2. Thus, we assume for subsession 2 that each (newly matched) group constitutes an independent matching group.

\subsection{Contributions}

First we analyze the average contributions to the public good, which are plotted separately for each treatment condition over the course of the experiment in Figure 1. In the first period, average contributions are almost the same in all conditions. Average contributions in the UN condition, however, are the highest throughout. 
This observation is supported by a Wilcoxon signed rank test, ${ }^{9}$ which finds that except for periods 1, 2 and 11, contributions under UN are significantly $(\alpha<5 \%)^{10}$ higher than under MA. The same holds when one compares UN with NO. The only exception is that NO and UN, furthermore, do not differ significantly in period 15.

Although average contributions in the NO condition are higher than in the MA condition in almost every round, the existing differences are not significant. ${ }^{11}$ Despite the wrong sign in the relation between NO and MA, we can thus not reject our behavioral Hypothesis 1.

OBSERVATION 1 In the unanimity (UN) referendum treatment condition, contributions are significantly higher than in both $M A$ and NO. There is no significant difference in contributions between conditions $M A$ and NO.

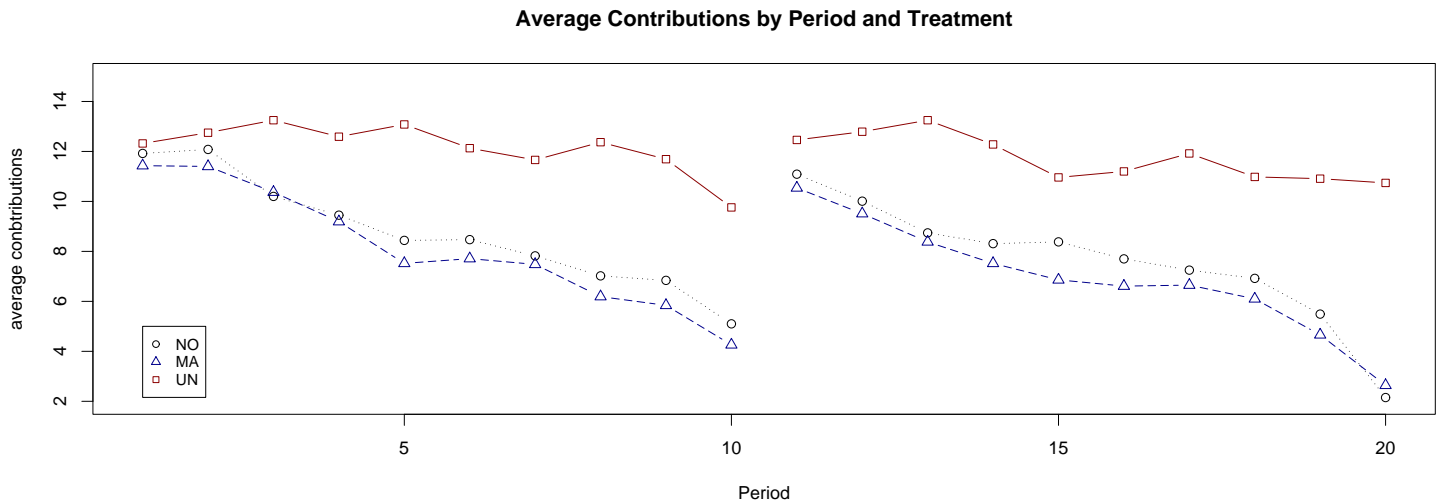

Figure 1: Average contributions over repetitions and treatments

For a more detailed analysis, we grouped individual contributions into classes of $g_{i}=0,6>g_{i}>0,11>g_{i}>5,16>g_{i}>10$, and $g_{i}>15$. The most noteworthy observation this allows is that the frequency of very high contributions $\left(g_{i}>15\right)$ in the UN mechanism remains unchanged throughout the experiment. Moreover, with respect to contributions, we can hardly identify an end game effect under the UN condition. In the other two treatment conditions, one can see that the most important source for a decrease in average contributions is the enormous increase in free riders $\left(g_{i}=0\right)$. While the frequency of intermediate contributions hardly change, the frequency of very high contributions decreases greatly.

\footnotetext{
${ }^{9}$ For the Wilcoxon signed rank test, only group averages are taken, thus assuming 20 independent observations.

${ }^{10}$ If not mentioned otherwise, significance levels are set to $\alpha<5 \%$ throughout.

${ }^{11}$ Note that except for period 19, the median contribution under NO is also higher than under the MA condition.
} 


\subsection{Voting Results}

Figure 2 shows the average rate of yes votes over the course of the experiments. The graph shows that the rate of yes votes is almost identical for conditions MA and UN. Condition NO, however, has on average a smaller rate of yes votes throughout the experiment, with the difference becoming larger over the course of the session. This observation is qualified by a Wilcoxon signed rank test. ${ }^{12}$ The former finds that there are no significant differences between the rate of yes votes in MA and UN in every round. However, in the first subsession, average yes rates under NO are significantly smaller than under MA (UN) in 6 (4) of the 10 periods. The frequency of significantly smaller yes rates under NO increases after the restart, with 9 (8) if compared to MA (UN) in subsession 2.

OBSERVATION 2 The rate of yes votes are identical in conditions UN and MA. Only if voting is merely cheap talk (condition NO) do subjects vote significantly less often for the provision.

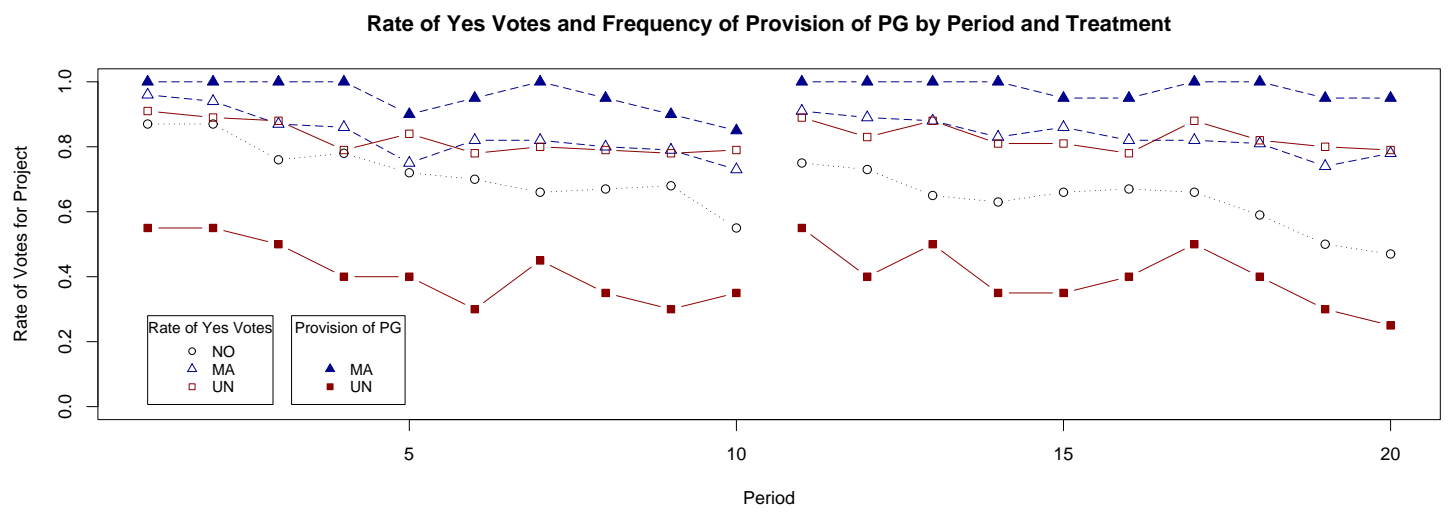

Figure 2: Average voting behavior

The same plot also shows the frequency of the outcome of the referendum for MA and UN. Although the rates of yes votes in conditions MA and UN differ only insignificantly, under MA the public good is provided significantly more often than under UN in every round. ${ }^{13}$

However, in order to test our Hypothesis 2 we need to control for contribution behavior. Table 1 reports the results of two different logit regressions on the outcome of the voting stages per matching group and period $\Phi_{m, t}$. More specifically the two logit estimations only use data from the UN and MA sessions, and the following

\footnotetext{
${ }^{12}$ Again, the test is based on group averages as independent observations.

${ }^{13} \chi^{2}$ test of homogeneity.
} 
mean function is assumed

$$
\operatorname{logit}^{-1}\left(\operatorname{Prob}\left(\Phi_{m, t}=1\right)\right)=\mathrm{x}_{m, 1}^{\prime} \beta+\varsigma_{m},
$$

where $\operatorname{Prob}\left(\Phi_{m, t}=1\right)$ stands for the latent probability that voting at period $t$ in matching group $m$ results in provision, $\mathrm{x}_{m}$ for the matrix of regressors, $\beta$ for the vector of (true) coefficients and $\varsigma_{m}$ for an unobserved random group effect (The usual assumptions concerning the random effects apply). In the first model (denoted as i) in Table 1, contribution behavior is controlled for by the inclusion of the sum $(G)$, variance (var), minimum ( $\min$ ) and maximum $(\max )$ of all contributions in group $m$ at period $t$. Most importantly, the regression result on the treatment dummy $D_{\mathrm{UN}}$ indicates:

OBSERVATION 3 Given the same contribution behavior, unanimity voting (UN) is significantly less likely to end in provision than majority voting (MA).

While the increase in the log likelihood is substantial, the relatively high standard deviation of the random effect indicates substantial heterogeneity between groups. ${ }^{14}$

However, there are more significant differences between treatment conditions which show up in the model ii of Table 1 (Best model according to the Akaike criterion and the Schwartz criterion). In contrast to model i, model ii does not include the minimum contribution. However, in addition, it includes two interaction effects with the treatment dummy ( $D_{\mathrm{UN}} G$ and $\left.D_{\mathrm{UN}} \max \right)$. First observe that while in MA the likelihood of provision is largely invariant to the sum of contributions $G$, it is significantly increasing in $G$ under UN. ${ }^{15}$ Finally, whereas under MA overall acceptance is significantly increasing in the maximum contribution it is - albeit weakly - significantly ${ }^{16}$ decreasing in max under UN.

These results illustrate the most important difference between the two voting mechanisms. Under MA voting, the maximum group contribution only increases the number of other players for whom provision is profitable and thus the likelihood that the maximum contributer will be exploited. Under unanimity, this is reversed since an increase in the maximum contribution increases the chance that the maximum contributer will prefer reimbursement and thus vetoes.

\subsection{Voting Behavior}

For a more elaborate analysis of the voting stage, we turn to the random effect logit estimation of individual voting behavior $\varphi_{i, t}$, listed in Table 2 . Here the dependent

\footnotetext{
${ }^{14}$ Due to the between subjects design no fixed effects estimation of the combined data is possible. To test whether random effects are applicable, separate fixed and random effects estimations for MA and UN data were compared in Hausman tests. The null of no differences can not be rejected in both cases (UN: $p=0.073$, MA: $p=0.095$ ), allowing us to assume strict exogeneity of the unobserved effects.

${ }^{15}$ The combination $G+D_{\mathrm{UN}} G$ remains significant $(p<0.001)$.

${ }^{16}$ With -0.275 the combined coefficient $\max +D_{\mathrm{UN}} \max$ is significant $(p=0.018)$.
} 
Table 1

Random Effect Logit of Voting Outcomes $\Phi_{m, t}(\mathrm{MA}$ and UN)

\begin{tabular}{|c|c|c|}
\hline & $\overline{\mathrm{i}}$ & ii \\
\hline constant & $2.961^{* *}(0.69)$ & $1.421 \quad(0.76)$ \\
\hline$D_{\mathrm{UN}}$ & $-8.273^{* *}(0.92)$ & $-4.989^{* *}(1.38)$ \\
\hline$G_{m, t}$ & $0.078^{* *}(0.02)$ & $-0.042 \quad(0.04)$ \\
\hline$D_{\mathrm{UN}} G_{m, t}$ & & $0.190^{* *}(0.05)$ \\
\hline $\operatorname{var}\left(\mathrm{g}_{m, t}\right)$ & $-0.022 \quad(0.02)$ & $-0.031^{* *}(0.01)$ \\
\hline $\min \left(g_{m, t}\right)$ & $0.158 \quad(0.10)$ & \\
\hline $\max \left(\mathrm{g}_{m, t}\right)$ & $-0.005 \quad(0.09)$ & $0.505^{* *}(0.16)$ \\
\hline$D_{\mathrm{UN}} \max \left(\mathrm{g}_{m, t}\right)$ & & $-0.780^{* *}(0.18)$ \\
\hline$\overline{\log \mathcal{L}}$ & -182 & -172 \\
\hline$\sigma_{\varsigma_{m}}\left(\sigma_{\text {resid. }}\right)$ & $1.819 \quad(0.502)$ & $2.015 \quad(0.552)$ \\
\hline
\end{tabular}

Note: ${ }^{*}: p<5 \%,{ }^{* *}: p<1 \%$. $\log \mathcal{L}$ of null model: -497 .

Standard errors in parentheses.

$\varphi_{i, t}$ equals one if subject $i$ voted for provision in period $t$ and is zero otherwise. The underlying assumptions are similar to those in the model of equation (6). This time, however, the data is on the individual level, implying that the unobserved random effect is also based on each subject $\left(\varsigma_{i}\right),{ }^{17}$ and the data of treatment condition NO is included in the analysis. In Table $2 g_{i, t}$ stands for subject $i$ 's intended contribution to the public good at period $t$; variable $G_{m(i), t}$ is the sum of contributions in matching group $m$ (where $i$ is a member) at $t$; $\operatorname{var}\left(\mathrm{g}_{-i, t}\right)$ is the variance of all contributions in group $m$ at $t$ by members other than $i$; and $D_{\max }$ is a dummy indicating that $i$ is the maximum contributer in his matching group. ${ }^{18}$ Variable $D_{\text {yes }>\text { no }}$ is a dummy indicating that, given the monetary incentives, the subject should prefer provision.

Again, $D_{\mathrm{UN}}\left(D_{\mathrm{NO}}\right)$ indicates the treatment dummy for treatment UN (NO). In order to test for effects of inequality aversion, we included variables indicating how a subject's contribution compares to those of the other group members. We define

$$
s_{i, t}=\left|\frac{g_{i, t}}{G_{m(i), t}}-\frac{1}{n}\right| \quad \text { if } G_{m(i), t}>0 \text { and } s_{i, t}=0 \text { otherwise. }
$$

Further, we set dummy $D_{g_{i}>\bar{g}}$ to indicate that $g_{i, t}$ is greater than the average contribution $G_{m(i), t} / n$. We can now measure inequality towards one's [dis]advantage by $\left[s_{i, t}^{+}=D_{g_{i}>\bar{g}} s_{i, t}\right] s_{i, t}^{-}=\left(1-D_{g_{i}>\bar{g}}\right) s_{i, t}$. Finally, we control for repetition effects via dummy $D_{\text {restart, }}$ indicating periods 11 to 20 and $\tau_{m}$, indicating which repetition matching group $m$ is playing $\left(\tau_{m} \in\{1, \ldots, 10\}\right)$. Multiplicative combinations of

\footnotetext{
${ }^{17}$ The inclusion of a matching group effect outside the subject effect proved to be unnecessary (LR-test: $p$-value $=0.213$ ).

${ }^{18}$ Note that the similarly defined variable $D_{\min }$ was also tested, but proved to be insignificant.
} 
Table 2

Random Effect Logit of Individual Voting Behavior $\varphi_{i, t}$

\begin{tabular}{lcclrlr}
\hline constant & 0.498 & $(0.54)$ & $D_{\mathrm{UN}}$ & $0.669(0.71)$ & $D_{\mathrm{NO}}$ & $-1.060^{*}(0.45)$ \\
$g_{i, t}$ & $-0.421^{* *}(0.05)$ & $D_{\mathrm{UN}} g_{i, t}$ & $0.164^{*}(0.08)$ & $D_{\mathrm{NO}} g_{i, t}$ & $0.214^{* *}(0.06)$ \\
$G_{m(i), t}$ & $0.148^{* *}(0.01)$ & $D_{\mathrm{UN}} G_{m(i), t}$ & $-0.058^{* *}(0.02)$ & $D_{\mathrm{NO}} G_{m(i), t}$ & $-0.060^{* *}(0.02)$ \\
$s_{i, t}^{+}$ & -0.015 & $(0.98)$ & $D_{\mathrm{UN}} s_{i, t}^{+}$ & $-8.858^{* *}(3.09)$ & $D_{\mathrm{NO}} s_{i, t}^{+}$ & $-4.505^{* *}(1.52)$ \\
$s_{i, t}^{-}$ & 3.220 & $(1.84)$ & $D_{\mathrm{UN}} s_{i, t}^{-}$ & $-1.862(4.00)$ & $D_{\mathrm{NO}} s_{i, t}^{-}$ & $-5.700^{*}(2.33)$ \\
$\operatorname{var}\left(\mathrm{g}_{-i, t}\right)$ & $-0.015^{* *}(0.002)$ & $D_{\max }$ & $-0.714^{* *}(0.17)$ & $D_{\text {yes }>\text { no }}$ & $2.542^{* *}(0.37)$ \\
$D_{\text {restart }}-0.818^{* *}(0.23)$ & $\tau_{m}$ & $-0.157^{* *}(0.03)$ & $D_{\text {restart }} \tau_{m}$ & $0.082^{*}(0.03)$ \\
\hline \multicolumn{2}{c}{$\log \mathcal{L}=-1570($ Null } & model: $\log \mathcal{L}=-3163) \sigma_{\varsigma_{i}}=1.123, \sigma_{\text {resid. }}=0.12345$ \\
\hline
\end{tabular}

Note: ${ }^{*}: p<5 \%,{ }^{* *}: p<1 \%$. Standard errors in parentheses. Estimation of variance covariance matrix via 50 bootstraps. Interaction effects not included are neither significant nor contribute to the accuracy of the estimation.

variables indicate interaction effects. Note that interaction effects not included in Table 2 are not significant; nor do they contribute to the accuracy of the estimation.

Looking first at the constant and the treatment dummies, one can see that there is no significant difference in the overall tendency to vote for provision between MA and UN. However, if voting becomes cheap talk (NO), the general tendency to vote for provision is significantly smaller than in MA and UN. Turning to reactions to contribution behavior, note that although the size of the coefficients differ significantly between treatments, the signs of the total effects on $g_{i, t}$ and $G_{m(i), t}$ remain significantly $(p$-value $<0.001)$ the same in all treatments. So, in all treatments, one's own contribution significantly decreases the tendency for yes votes while the sum of contributions significantly increases the tendency for yes votes. However, in treatments UN and NO, these reactions are significantly smaller than in treatment MA.

Not surprisingly, there are less yes votes with increasing heterogeneity in group contributions $\left(\operatorname{var}\left(\mathrm{g}_{m, t}\right)\right)$ and if someone is the maximum contributer $\left(D_{\max }\right)$. Furthermore, if provision is optimal, subjects are more likely to vote for it.

As we could observe above, cooperativeness, as signaled by intended contributions decreases with the number of repetitions within one matching group. The same can be observed concerning the yes votes $\left(\tau_{m}\right)$. There is a similar negative shift after the restart $\left(D_{\text {restart }}\right)$. This shift is only mildly compensated for by a slight decrease in the reactivity to the number of repetitions $\left(D_{\text {restart }} \tau_{m}\right)$. Still, the overall reaction to the number of repetitions $\left(\tau_{m}+D_{\text {restart }} \tau_{m}\right)$ remains significantly negative $(p$-value $=0.004)$.

OBSERVATION 4 The general tendency to vote for provision decreases with the number of repetitions. Directly after the restart, it increases again, albeit to a lower level than in the very first round.

Concerning inequality, there are again interesting differences. In the MA treatment, 
yes votes hardly react to inequality in contributions. Under unanimity, this changes tremendously. The more that someone contributed more than others and thus, the more unequal the payoffs are - to his disadvantage - the more likely someone will veto by not voting for provision $\left(s_{i, t}^{+}+D_{\mathrm{UN}} s_{i, t}^{+}=-8.873\right.$ significant at $p$-value $\left.=0.003\right)$. On the other hand, inequality that is to one's advantage has no influence on voting behavior. Despite significant differences towards other treatments, qualitatively the same holds for the NO condition: Inequality that is to one's disadvantage results in significantly less yes votes $(p$-value $<0.001)$. Although, in condition NO, the overall reaction to inequality that is to one's advantage is negative, with $\overline{s_{i, t}^{-}}+D_{\mathrm{NO}} s_{i, t}^{-}=$ -2.475 , this remains insignificant $(p$-value $=0.088)$.

OBSERVATION 5 Inequality only significantly affects the acceptance of provision in treatments UN and NO, and here, only if it is to the decider's disadvantage. The highest effects can be observed if voting is merely cheap talk (NO).

In the theoretical analysis, we excluded certain voting equilibria in weakly dominated strategies by assuming "sincere" voting. Looking at actual voting behavior, this assumption appears reasonable. Over all periods, $88.3 \%$ and $89.5 \%$ voted "sincerely" in the two relevant voting conditions, MA and UN. The smallest frequency, of only $73.9 \%$, can be observed in treatment NO. Opposed to any strategic argument in favor of these equilibria, the frequency of "sincere" votes is highest in the first periods of a subsession (98\% in MA and UN).

\subsection{Efficiency}

So, which referendum design yields more efficient outcomes? There are several answers to Hypothesis 3. If we refer to cases in which the public good is provided, profits under unanimity voting are significantly higher than in any other voting mechanism, whereas under MA and NO they only differ insignificantly. Figure 3 plots in the first panel average profits for those cases where the public good is provided.

OBSERVATION 6 If the public good is finally provided, the majority voting mechanism (MA) yields no higher profits than automatic provision (NO). Under unanimity voting (UN), however, profits are significantly higher than with any other mechanism.

However, if we refer to the average overall profits, we find the opposite result. The second panel in Figure 3 plots the average profits of subjects separately for each treatment condition. Observe that almost throughout the experiment, it holds that NO is more efficient than MA, which in turn yields higher profits than UN.

Surprisingly, however, most of these differences are not significant. This is largely due to a very high variance of average group profits, especially under UN in early rounds. Consequently only differences in later rounds of a subsession between NO 
Average Profits if $P G$ is Provided by Period and Treatment

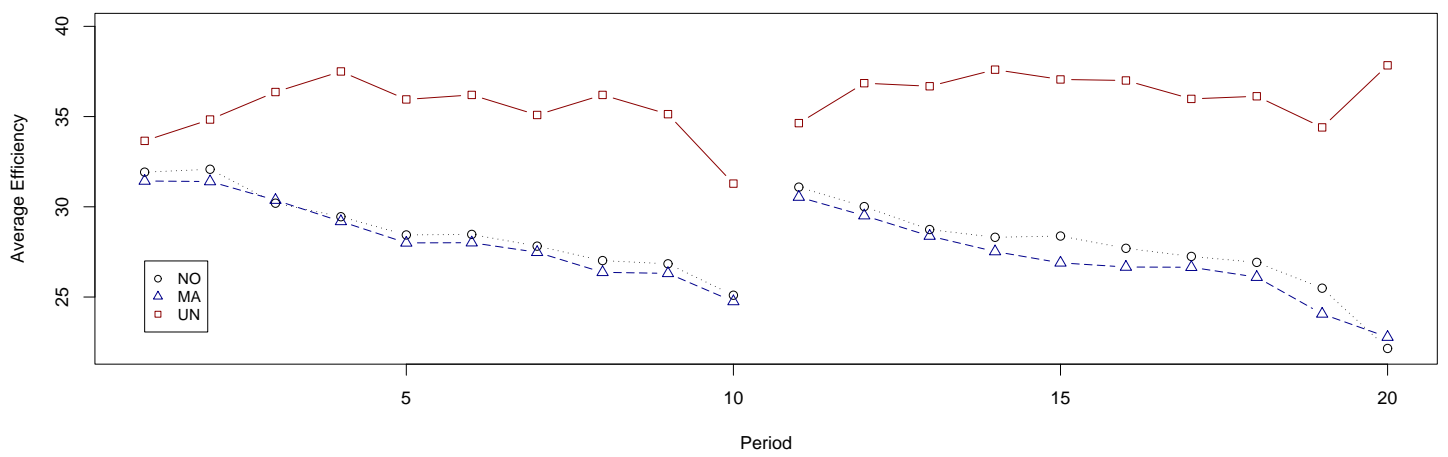

Average Profits by Period and Treatment

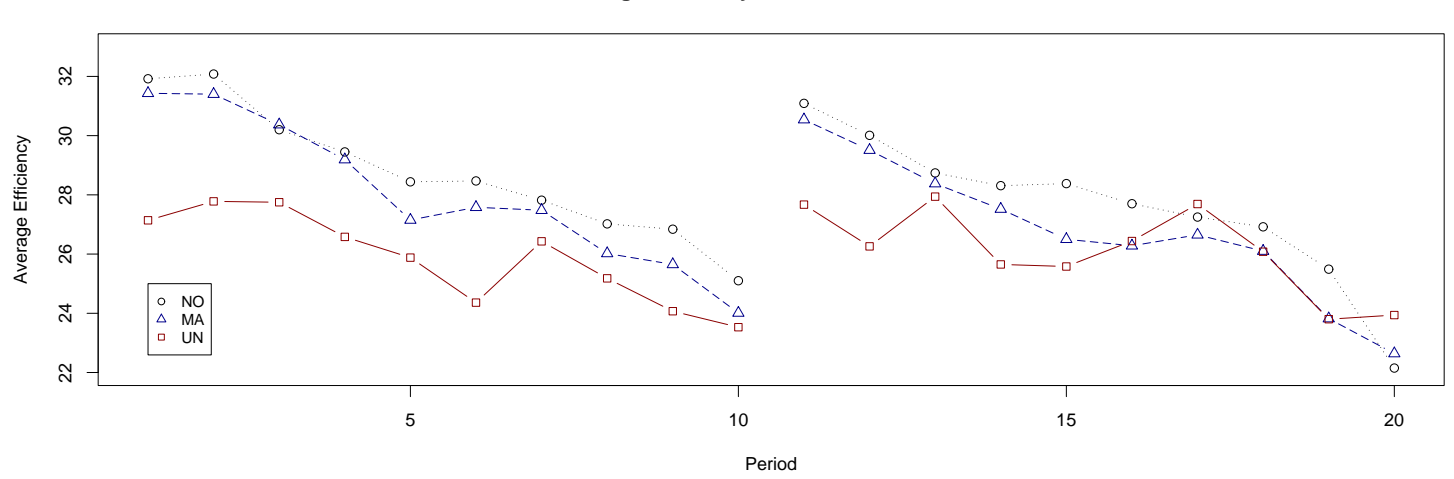

Figure 3: Average profits 
and UN, on the one hand, and MA and UN, on the other hand, become significant. There are no significant differences between NO and MA.

OBSERVATION 7 Majority voting (MA) does not yield significantly different profits when there is automatic provision (NO). On average, unanimity voting (UN) yields smaller profits than either $M A$ or NO.

\section{Discussion}

This study experimentally explored effects of ex interim referendums on the voluntary provision of public goods. Particularly, we have tested whether an unanimity or majority ex interim referendum enhances voluntary contributions and overall efficiency in a public good game. As a baseline treatment, we introduced a cheap talk referendum where subjects could only communicate their satisfaction with the intended contributions, without affecting outcomes.

Theoretically, assuming "sincere" voting, all games have a zero contribution subgame perfect equilibrium. Behaviorally there are, however, important differences. Cooperative players in the game with automatic provision risk exploitation. This risk is already reduced if provision must be accepted by a majority and unanimity voting eliminates this risk completely. Due to this "safeguard effect", we expected the highest contributions for unanimity voting and the smallest for automatic provision.

As in most public good experiments, we observed substantial contributions in all treatment conditions. Throughout the experiment, contributions were highest under unanimity voting. Furthermore, intended contributions in the unanimity mechanism remained very high even in very late periods of each subsession. A decline in cooperation in the unanimity condition could only be observed if there was a decline in acceptance of provision. Overall, the high rates of rejection in the unanimity mechanism rendered it less efficient than the other conditions. Hereby it is not individual voting behavior but primarily the mechanism which drives this result. Individual voting behavior only differs substantially if votes are merely a communication device (NO).

Interestingly, majority voting - if compared to the baseline condition - hardly differs in contributions and outcomes. To some extent, this result may be driven by the chosen productivity of the public good. Given identical contribution patterns, the number of subjects preferring provision is affected by the productivity of the good. Further research is needed in order to find a final answer to the question whether majority voting yields different results in public good provision conditions in which players can communicate their satisfaction with the intended contributions.

For economic policy these results have very specific implications. If the priority lies on the quality of an agreement, unanimity voting clearly is the mechanism of choice. More importantly, under repeated interaction, unanimity is better able to keep intended contributions on a high level. So, if there are other instruments 
available that can efficiently broker agreements, unanimity should be able to yield the best results in the long run. However, if this is not the case, a simple or qualified majority mechanism may be better. In a repeated interaction environment this entails the risk that some partners will become very uncooperative, and thus the unity of the group might be threatened.

\section{Appendix A: Proof of Proposition 1}

Let us assume that players always vote for (or against) the public good if they earn more (or less) when the public good is provided than if it is not. Obviously, since one's payoff increases with the size of the public good but decreases with one's own contribution, group members who did not contribute vote for the provision of the public good for any $G \geq 0$. However, for players who contributed to the public good $\left(\delta_{i}=1\right)$, a simple calculation of payoffs yields that they vote for the provision if

$$
g_{i} \leq \alpha G+f .
$$

Given the ordered set of contributions in a decreasing sequence $\mathrm{g}=\left\{g_{1}, g_{2}, \ldots, g_{n}\right\}$ with $g_{i} \geq g_{i+1}$, we find the following:

LEMMA 1

$$
\begin{aligned}
& \varphi_{i}=1 \Rightarrow \varphi_{i+1}=1 ; \\
& \varphi_{i+1}=0 \Rightarrow \varphi_{i}=0 .
\end{aligned}
$$

\section{A.1 Unanimity}

Using Lemma 1, we derive directly

Proposition 2 Under unanimity voting, the public good is provided if the player who contributed the most prefers provision, which is the case for $g_{1} \leq \alpha G+f$.

We can now reduce the two stage game to a one stage game by replacing the last stage with it's solution outcome. The resulting reduced strategic form game has a modified payoff function: Subject $i$ 's payoff is defined as in equation (3). The only difference is that now $\Phi$ is defined as a function of $g_{1}, G$ and $f$ as follows:

$$
\Phi(\varphi)=\left\{\begin{array}{l}
1 \text { if } g_{1} \leq \alpha G+f \\
0 \text { otherwise }
\end{array}\right.
$$

One can consider the reduced game as a coordination game between the player with the highest contribution and all other players who, with their contributions, keep the rejection by the former player unprofitable. In the following, by $\mathrm{g}_{-i}$ and $G_{-i}$ we define the set and sum, respectively, of contributions by players other than 
$i$. That is, $\mathrm{g}_{-i}=\mathrm{g} \backslash\left\{g_{i}\right\}$ and $G_{-i}=\sum_{j \neq i} g_{j}$. Furthermore, $m$ defines the player with the maximum contribution in $\mathrm{g}_{-i}$ and $g_{-i}^{m}$ defines his contribution; that is,

$$
g_{-i}^{m}=\max _{j}\left\{g_{j} \mid g_{j} \in \mathrm{g}_{-\mathrm{i}}\right\}
$$

Finally, let $G_{-i}^{-m}$ denote the sum of contributions by players other than $i$ and $m$, that is,

$$
G_{-i}^{-m}=\sum_{j \neq i, j \neq m} g_{j}
$$

Given the set of contributions by other players $g_{-i}$, we can derive player $i$ 's best response $g_{i}^{*}$ such that her contribution holds $m$ indifferent about voting for or against the provision; or, if that is not profitable or is not possible, $i$ best responses by contributing nothing.

$$
g_{i}^{*}= \begin{cases}\frac{1-\alpha}{\alpha} g_{-i}^{m}-G_{-i}^{-m}-\frac{f}{\alpha} & \text { if } 0<g_{i}^{*} \leq \frac{\alpha}{1-\alpha} G_{-i} \text { and } g_{i}^{*} \leq e_{i} \\ 0 & \text { otherwise }\end{cases}
$$

The first equation in (A4) guarantees that $m$ is indifferent, whereas the first condition in the same line guarantees that this is still possible and profitable for $i$. For the relation between $g_{i}^{*}$ and $g_{-i}^{m}$, we find the following:

Proposition 3 For every $g_{-i}^{m}>0$ and $g_{i}^{*}>0$, it follows that $g_{i}^{*}<g_{-i}^{m}$.

Proof The first part of (A4) can be rearranged to

$$
G_{-i}^{-m}=\frac{1-\alpha}{\alpha} g_{-i}^{m}-g_{i}^{*}-\frac{f}{\alpha} .
$$

Assuming $g_{i}^{*}>0$, we substitute the profitability condition

$$
g_{i}^{*} \leq \frac{\alpha}{1-\alpha}\left(G_{-i}^{-m}+g_{-i}^{m}\right)
$$

from (A4) for $g_{i}^{*}$. This yields the relation

$$
G_{-i}^{-m} \geq \frac{1-2 \alpha}{\alpha} g_{-i}^{m}-\frac{1-\alpha}{\alpha} f
$$

This relation can now be reinserted into (A4), yielding $g_{i}^{*} \leq g_{-i}^{m}-f$ and thus $g_{i}^{*}<g_{-i}^{m} \quad \forall f>0$.

Let us now take again any ordered set $\mathrm{g}^{+}$with at least some positive contributions, i.e. $g_{1}^{+}>0$ and $G^{+}>0$. From Proposition 3 we can conclude that the best response of the maximum contributer, who contributes $g_{1}^{+} \geq g_{2}^{+}$, is to contribute a $g_{1}^{*}$, for which it holds that $g_{1}^{*}<g_{2}^{+}$, and thus $g_{1}^{*}<g_{1}^{+}$. Consequently, for the reduced game there is no fix point according to the best replies for any $G>0$. The only fix point exists for $G=0$, which proves Proposition 1 for the game with unanimity voting. 


\section{A.2 Majority}

Applying Lemma 1 we can show that a simple variation of Proposition 2 holds for the public good game with majority voting. Yet, there are smaller majority coalitions. Let us consider once again the ordered set of contributions $g_{-i}$ for all players other than $i$. We define $l$ as that subject in the ordered set $g_{-i}$ for whom it holds that

$$
n-l+1>l-1 \text { and } n-l \leq l \text {. }
$$

By Lemma 1 we know that if player $l$ prefers provision, all players with lower contributions $(l+1, \ldots, n-1)$ do as well. Thus the coalition of players $\{l, l+1, \ldots, n-$ 1 f from $g_{-i}$, together with a best replying $i$, constitute a minimum winning coalition, preferring provision. We can thus form a reduced game by again replacing the voting stage with it's solution outcome, which is provision if $g_{l} \leq \alpha G+f$ and no provision otherwise. Consequently, the best reply function changes to

$$
g_{i}^{*}= \begin{cases}\frac{1-\alpha}{\alpha} g_{-i}^{l}-G_{-i}^{-l}-\frac{f}{\alpha} & \text { if } 0<g_{i}^{*} \leq \frac{\alpha}{1-\alpha} G_{-i} \text { and } g_{i}^{*} \leq e_{i} \\ 0 & \text { otherwise }\end{cases}
$$

where $g_{-i}^{l}$ defines the contribution of player $l$, and $G_{-i}^{-l}$ the sum of contributions by players other than $i$ and $l$, that is, $G_{-i}^{-l}=\sum_{j \neq i, j \neq l} g_{j}$.

Obviously, we can apply Proposition 3 within the (minimum) majority subset $\{l, l+1, \ldots, n\}$. Hence, Proposition 1 also holds for the public good provision game with a majority referendum.

\section{Appendix B: Instructions ${ }^{19}$}

Thank you for participating in our experiment. In this experiment, you will make decisions by which you can earn money. How much you will earn depends on your decisions and the decisions of the other participants. Please read these instructions very carefully.

These instructions are for your private information. We kindly ask you to refrain from any attempts to communicate directly with other participants. If you do have any questions, please raise your hand and one of the persons who run the experiment will come to your place and clarify your questions. In case you violate this rule, we will have to exclude you from this experiment.

During the experiment, you can earn points, which will be exchanged for Euros at the end of the experiment. The exchange rate is 75 points for 1 Euro. At the beginning of the experiment, you will be assigned to groups of five participants. No participant, but only the experimentors are able to identify the other participants in

\footnotetext{
${ }^{19}$ This is our own translation of the German instructions for the MA treatment. Differences in the UN and in the NO treatments are marked by footnotes.
} 


\section{The decision task}

We will inform you about the exact setting of the experiment later. In what follows we describe the the general setting. Below the general descriptions you find a control questionnaire, which will help you to understand the rules for the decision task.

You will be matched in groups of five players each. Each member of the group has to decide how to invest 20 points. You can invest them for a private project or you can invest some or all of them for for a public project. Each point which is not invested in the public project will be automatically assigned to the private project.

Your income from the private project

For each point you invest for the private project you earn one point. For instance, if you invest 20 points for the private project (and, thus, invest nothing for the public project) you earn 20 points from the private project. If you invest 1 point for the private project, you earn 1 point from the private project. Nobody except you receives any income from your private project.

\section{Your income from the public project}

All group members earn for each point you invest for the public project as well as you earn for each point any other group member invests for the public project. For each group member, the income from the public project is as following:

income from the public project $=$ sum of all investments for the public good $\times 0.4$

For instance, if all investments for the public good sum up to 12 points you and each other group member earns $12 \times 0.4=4.8$ points from the public project. For instance, if all investments for the public good sum up to 2 points you and each other group member earns $2 \times 0.4=0.8$ points from the public project.

\section{Your total income}

Your total income is the sum of your earnings from the private project and your earnings from the public project. Thus

$$
\begin{gathered}
\text { your earnings from the private project } \\
(=20-\text { your investment for the public project }) \\
+ \text { your earnings from the public project }
\end{gathered}\left(\begin{array}{c}
=0.4 \times \text { sum of all investments for the public project }) \\
=\text { total income } \\
\text { Detailed instructions }
\end{array}\right.
$$

In total, you will interact with the other participants for $2 \times 10$ rounds. In each round, you and four other participants will be matched in groups of five. For round 1 to round 10, you will interact with the same four group members. In round 11, you will be matched with four other participants and interact with them from round 11 to round 20 . 


\section{Detailed description of each round}

At the beginning of each round you and all other group members will be asked to decide how many points you wish to invest for the public project. Thereafter, we will inform you about the investments of all the other group members, and ask you to vote for or against the public project. Your vote tell us whether you would like the public project to be paid out according to the rule described above, or whether all group members who invested in the public project will be reimbursed these points, minus 1 point, for their private project.

If at least 3 members of a group vote for it, the public project will paid out according to the rules described above. If three or more vote against the public project, the total income in that round for all group members who invested 1 or more points for the public project will be 19 points, while the total income in that round for all group members who invested nothing for the public project will be 20 points. $^{20}$

At the end of each round, you will be informed about the incomes and the decisions of all group members.

\section{References}

Banks, J., C. Plott, And D. Porter [1988], "An Experimental Analyisis of Unanimity in Public Goods Provision Mechanisms," Review of Economic Studies, 55, 301-322.

Chaudhuri, A., S. Graziano, and P. Maitra [2006], "Social Learning and Norms in a Public Good Experiment with Inter-Generational Advice," Review of Economic Studies, 73, 357-380.

Cinyabuguma, M., T. Page, and L. Putterman [2005], "Cooperation under the Threat of Expulsion in a Public Goods Experiment," Journal of Public Economics, 89, $1421-1435$.

Ehrhart, K.-M. And C. Keser [1999], "Mobility and Cooperation: On the Run," Working Paper 99s-24, CIRANO, Montreal.

Fehr, E., AND S. GÄChter [2000], "Cooperation and Punishment in Public Good Experiments," American Economic Review, 90, 980-994.

Feld, L., And J. Matsusaka [2003], "Budget Referendums and Government Spending: Evidence from Swiss Cantons," Journal of Public Economics, 87, 2703-2724.

- - AND J.-R. TyRan [2002], "Tax Evation and Voting: An Experimental Analysis," Kyklos, 55, 197-222.

FischBACHER, U. [1999], "Z-Tree: A Toolbox for Readymade Economic Experiments," Working Paper 21, Institute for Empirical Research in Economics, University of Zurich.

${ }^{20}$ For the UN treatment "If all members of the group vote for it, the public project will be paid out according to the rules described above. If one or more vote against the public project, the total income in that round for all group members who invested 1 or more points for the public project will be 19 points, while the total income in that round for all group members who invested nothing for the public project will be 20 points." For the NO treatment "Your vote and the votes of all other group members do not affect whether the public project is paid out. In any case, your earnings from the public and the private project follow the rules described above." 
- -, S. Gächter, And E. Fehr [2001], "Are People Conditionally Cooperative? Evidence from a Public Goods Experiment," Economics Letters, 71, 397-404.

Frey, B. [1994], "Direct Democracy: Politico-Economic Lessons from Swiss Experience," American Economic Review, 84, 338-342.

Greiner, B. [2004], "An Online Recruitment System for Economic Experiments," pp. 79-93 in: K. Kremer and V. Macho (eds.), Forschung und wissenschaftliches Rechnen 2003, Gesellschaft für Wissenschaftliche Datenverarbeitung, Göttingen, GWDG Bericht 63.

Groves, T., And J. Ledyard [1977], "Optimal Allocation of Public Goods: A Solution to the 'Free Rider' Problem," Econometrica, 45, 783-809.

Hirshleifer, D., AND R. Rasmusen [1989], "Cooperation in a Repeated Prisoners' Dilemma with Ostracism," Journal of Economic Behavior and Organization, 12, 87106.

Isaac, R., K. McCue, And C. Plott [1985], "Public Good Provision in an Experimental Environment," Journal of Public Economics, 26, 51-74.

Ledyard, J., AND T. PAlfrey [1999], "A Characterization of Interim Efficiency with Public Goods," Econometrica, 67, 435-448.

- AND - [2002], "The Approximation of Efficient Public Good Mechanisms by Simple Voting Schemes," Journal of Public Economics, 83, 153-171.

Masclet, D., C. Noussair, S. Tucker, And M.-C. Villeval [2003], "Monetary and Nonmonetary Punishment in the Voluntary Contribution Mechanism," American Economic Review, 93, 366-380.

Moxnes, E., And E. Van der HeiJden [2003], "The Effect of Leadership in a Public Bad Experiment," Journal of Conflict Resolution, 47, 773-795.

Ostrom, E., J. Walker, And R. Gardner [1992], "Covenants with and without a Sword: Self-Governance is Possible," American Political Science Review, 86, 404-417.

Page, T., L. Putterman, And B. Unel [2005], "Voluntary Association in Public Good Experiments: Reciprocity, Mimicry and Efficiency," The Economic Journal, 115, 10321053.

Pommerenne, W. [1978], "Institutional Approaches to Public Expenditure: Empirical Evidence from Swiss Municipalities," Journal of Public Economics, 9, 255-280.

Potters, J., M. Sefton, And L. Vesterlund [2005], "After you - Endogenous Sequencing in Voluntary Contribution Games," Journal of Public Economics, 89, 13991419 .

Romer, T., H. Rosenthal, And V. Munley [1992], "Economic Incentives and Political Institutions: Spending and Voting in School Referenda," Journal of Public Economics, $49,1-33$.

Schimmelfennig, F., And U. Sedelmeier [2002], "Theorizing EU Enlargement: Research Focus, Hypotheses, and the State of Research," Journal of European Public Policy, 9, 500-528.

Smith, V. [1980], "Experiments with a Decentralized Mechanism for Public Good Decisions," The American Economic Review, 70, 584-599. 
Sven Fischer

Max Planck Institute of Economics

Kahlaische Str. 10

07745 Jena

Germany

Email:

fischer@econ.mpg.de

Andreas Nicklisch

Max Planck Institute for Research on Collective Goods

Kurt-Schumacher-Straße 10

53313 Bonn

Germany

Email:

nicklisch@coll.mpg.de 